University of Nebraska - Lincoln

DigitalCommons@University of Nebraska - Lincoln

USDA National Wildlife Research Center - Staff Publications
U.S. Department of Agriculture: Animal and Plant Health Inspection Service

June 2002

\title{
Aerosolized essential oils and individual natural product compounds as brown treesnake repellents
}

Larry Clark

USDA/APHIS/WS National Wildlife Research Center, larry.clark@aphis.usda.gov

John Shivik

United States Department of Agriculture, Animal and Plant Health Inspection Service, Wildlife Services, National Wildlife Research Center

Follow this and additional works at: https://digitalcommons.unl.edu/icwdm_usdanwrc

Part of the Environmental Sciences Commons

Clark, Larry and Shivik, John, "Aerosolized essential oils and individual natural product compounds as brown treesnake repellents " (2002). USDA National Wildlife Research Center - Staff Publications. 471. https://digitalcommons.unl.edu/icwdm_usdanwrc/471

This Article is brought to you for free and open access by the U.S. Department of Agriculture: Animal and Plant Health Inspection Service at DigitalCommons@University of Nebraska - Lincoln. It has been accepted for inclusion in USDA National Wildlife Research Center - Staff Publications by an authorized administrator of DigitalCommons@University of Nebraska - Lincoln. 


\title{
Aerosolized essential oils and individual natural product compounds as brown treesnake repellents ${ }^{\dagger}$
}

\author{
Larry Clark* and John Shivik \\ United States Department of Agriculture, Animal and Plant Health Inspection Service, Wildlife Services, National Wildlife Research Center, \\ 4101 La Porte Avenue, Fort Collins, CO 80521 USA
}

\begin{abstract}
Chemical irritants useful as repellents for brown treesnakes (Boiga irregularis) were identified. Exposure to various compounds produced a range of intensities for locomotory behavior in snakes. Essential oils comprised of $10 \mathrm{~g} \mathrm{liter}^{-1}$ solutions of cedarwood, cinnamon, sage, juniper berry, lavender and rosemary each were potent snake irritants. Brown treesnakes exposed to a 2-s burst of aerosol of these oils exhibited prolonged, violent undirected locomotory behavior. In contrast, exposure to a $10 \mathrm{~g} \mathrm{liter}^{-1}$ concentration of ginger oil aerosol caused snakes to locomote, but in a deliberate, directed manner. We also tested specific compounds, all derivative of food and flavor ingredients. $10 \mathrm{~g}$ liter $^{-1}$ solutions delivered as aerosols of $m$-anisaldehyde, trans-anethole, cineole, cinnamaldehyde, citral, ethyl phenylacetate, eugenol, geranyl acetate or methyl salicylate all acted as potent irritants for brown treesnakes. The individual ingredients were classified using cluster analysis into groups that promoted different levels of response by snakes. This study is the first to systematically investigate the irritant potential of natural products for snakes. These data will be useful in the development of practical pest management tools for snakes.

Published in 2002 for SCI by John Wiley \& Sons, Ltd.
\end{abstract}

Keywords: animal control; behavior; brown treesnake; Boiga irregularis; conservation; Guam; non-lethal; pest control; repellents; wildlife management

\section{INTRODUCTION}

The number of chemical control agents for vertebrate pests reflects strategic and commercial needs and demand for these products with their availability depending upon the taxon. For example, as of 1998, 61 different active ingredients were registered as mammal control agents with the United States Environmental Protection Agency (US EPA) under the Federal Insecticide, Fungicide, and Rodenticide Act (FIFRA). ${ }^{1}$ A review of the US EPA Pesticide Database shows that $41 \%$ of these compounds function as lethal control agents, while $59 \%$ were considered to be nonlethal control agents, ie repellents. Fewer chemical agents $(n=10)$ are available for bird control: $40 \%$ of these agents are used for lethal control, while $60 \%$ are used in non-lethal control products. ${ }^{2}$ Rarer still are agents available for control of reptiles $(n=2)$. The first product is methyl bromide, and it is used as a lethal fumigant (US EPA Reg No 5785-41). ${ }^{3}$ The second product is advertised as a snake repellent and contains naphthalene and sulfur as active agents (US EPA Reg No 058630-00001). ${ }^{4}$ From these data one might assume that snake control is not an area of large commercial, ecological or pest management concern.
While it is arguable how large a commercial demand there is for snake control methods, there is a case to be made for the strategic need for such methods. We use the case history of the brown treesnake (Boiga irregularis) as an example of this strategic need and as a rationale for the development of new snake control methods.

\subsection{Strategic need for snake control methods}

Brown treesnakes found their way to the island of Guam as stowaways in cargo during the late 1940s or early 1950s. ${ }^{5}$ Over the years the population on Guam has irrupted, achieving densities of 50-100 snakes per ha. ${ }^{6}$ Ecologically, this snake population explosion has been devastating to the island's ecology. Nine of eleven endemic island birds, two lizards and one bat have been driven to extinction by this effective and abundant predator. The high population densities of snakes has also affected the island's economy, principally by causing power outages when this arboreal snake shorts out electrical power substations. ${ }^{7}$ As part of a containment program, the US Department of Agriculture traps and removes snakes around cargo ports to reduce the likelihood that snakes will emigrate

\footnotetext{
* Correspondence to: Larry Clark, United States Department of Agriculture, Animal and Plant Health Inspection Service, Wildlife Services, National Wildlife Research Center, 4101 La Porte Avenue, Fort Collins, CO 80521, USA

${ }^{\dagger}$ This article is a US Government work and is in the public domain in the USA

Contract/grant sponsor: US Department of Defense; contract/grant number: Legacy Project Number 18

(Received 15 June 2001; revised version received 7 February 2002; accepted 2 April 2002)
} 
to other islands, eg Hawaii. ${ }^{8}$ In addition to the efforts to reduce local populations around high-risk shipping and airports, the USDA is developing toxicants to reduce snake populations, and inspects cargo using dogs trained to detect snakes. ${ }^{8,9}$ Multiple methods may be needed to control snake populations and control their movement in and around points of exit on Guam. In this study we review the extant methods for snake control and identify a strategic need for human and environmentally safe snake repellents. The experiments described herein identify novel snake repellents derived from essential oils and some of their individual chemical constituents.

\subsection{Snake control methods}

Although there are few US EPA-registered snakecontrol products, modest research efforts to discover and develop effective snake-control methods have occurred and these methods can be categorized as belonging to one of two functional categories: prophylactic or remedial. Prophylactic methods are designed to prevent snakes from accessing areas to be protected, where as remedial methods are designed to extirpate snakes once they have entered an area where they are not desired.

\subsubsection{Prophylactic methods for snake control}

Examples of prophylactic approaches for snake exclusion include physical and chemical barriers. Fences of various designs have been experimentally evaluated, and in some cases operationally employed, to exclude snakes from areas. Besides being constructed of material that prevents snakes from passing through the barrier, the fences often are constructed of material that snakes cannot easily climb. ${ }^{10-12}$ Some fence designs include overhangs or are entirely angled such that arboreal snakes cannot maintain sufficient leverage to pass over the fence. ${ }^{13,14}$ Other fence designs include the use of electrical wires as added deterrent strategies. $^{15-18}$

Additional exclusion techniques include the application of polybutene products or other sticky substances to surfaces to which snakes avoid contact. ${ }^{19,20}$ Irritating chemical barriers, ie repellents, also may be used as a method of exclusion. Because of their acute chemical sensibility, snakes are presumed not to cross these barriers owing to the chemicals' noxious properties. ${ }^{4}$ The success of this method varies depending upon chemical used and target snake species tested. ${ }^{3,21-26}$ However, even in cases where the snake is known to be responsive to a chemical, its use as a barrier is generally not effective because the snake can circumvent the irritant by arching over it. ${ }^{27}$ In other circumstances it may be impractical to employ enough repellent to treat large areas to achieve exclusion because of environmental and economic constraints regulating the use of large amounts of repellent chemical. $^{14}$

\subsubsection{Remedial methods for snake control}

Remedial methods generally require a higher degree of interaction by the snake with the control method, which in turn implies that the snake has already invaded the area to be protected. These control methods are comprised of lethal and non-lethal methods.

Lethal control methods include the use of chemicals as toxicants administered either orally, dermally or via the respiratory system as a fumigant. ${ }^{3}$ Orally delivered toxicants tested include acetaminophen, DDT, potassium chloride, nicotine sulfate and strychnine. ${ }^{9,28-32}$ Dermally administered toxicants tested include bromophos, chlordane, dimpylate, methomyl and various pyrethrins. $^{33-36}$ Fumigants effective against snakes include calcium cyanide, chlorine, tetrachlorethane, carbon bisulfide, formaldehyde, methyl bromide and aluminum phosphide. ${ }^{9,28,30,37-39}$

Traps and glue boards may also be used. ${ }^{40}$ Whether such methods are considered lethal depends upon the intention of the operator. Generally the snake is livecaptured or restrained and the operator determines the fate of the snake.

Chemicals also may be used to motivate a snake to abandon a refugium once it has entered. Application of these compounds may be in the form of aerosols or vapors. Such compounds most likely are irritating and function by promoting escape behavior. Efforts to identify snake irritants have largely focused on compounds with low human safety attributes. For example, various forms of ammonia, sulfides and sulfurs, pyrethrums, organophosphates, dichlorobenzenes, naphthalene, creosotes, kerosine, hydrocarbon fuels, all have been tried with some success. ${ }^{14,20-23,25}$

The use of chemical repellents as a remedial method to drive snakes out of enclosed spaces is a better use of the repellent relative to its use as a prophylactic method of exclusion. ${ }^{14}$ Vapors or aerosols can be concentrated in enclosed spaces to levels where they are likely to exceed the tolerance threshold of a snake. In contrast, because of the diluting potential of open air spaces, the chemical may never attain vapor concentrations sufficient to be repellent to snakes, or if such concentrations are achieved the amount of chemical necessary to maintain the barrier would be prodigious. $^{14}$

Despite the advantages of using chemicals as remedial repellents, the compounds tested are largely derived from existing pesticides or other hydrocarbon products. These chemicals generally are associated with human and environmental health and safety concerns. Thus, there is a strategic need to identify repellents that can be used to drive snakes out of their refugia but that present low risk to human health and safety. This research is an effort to identify natural products and human food grade products with well-described human safety information that might also serve as snake repellents. Such compounds would significantly reduce registration costs 
because significant waivers for toxicity testing could be obtained. ${ }^{41,42}$

\section{METHODS}

\subsection{Study subjects}

Brown tree snakes $(n=400)$ were captured on the island of Guam along forest-jungle edge using modified minnow traps with live mice lures or by hand after being spot-lighted on fences. ${ }^{43}$ Snakes were individually housed in plastic containers $(0.23 \times 0.25 \times$ $0.45 \mathrm{~m}$ ) and maintained on a $12: 12 \mathrm{~h}$ light:dark cycle inside a military warehouse on Andersen Air Force Base, Guam. Capture of snakes occurred during three separate visits to the island: 1997, 1998, 1999. Capture, maintenance and testing were carried out in accordance to Institutional Animal Care and Use guidelines.

\subsection{Stimuli}

Bioassays were conducted using essential oils and reagent grade compounds (Tables 1 and 2). Essential oils and other aroma products were selected and purchased based upon their retail availability (Aromasys, Inc). Reagents used in the tests were selected because they were often the principal compound in the essential oils, or they were the principal detectable sensory agent of the essential oil to humans. ${ }^{44,45}$ Reagents were purchased from Aldrich Chemical Co, Milwaukee, Wisconsin. Tests solutions were prepared using test stimulus + aqueous powdered yucca (Yucca schidigera) solution ( $30 \mathrm{~g} \mathrm{liter}^{-1}$ ), + water $(1+1+98$ by weight). Because the test stimuli were water-insoluble, the yucca solution was used to create stable emulsions.

\subsection{Aerosol tests}

For testing, the holding tub was moved to the observation room and the solid lid was replaced with a lid with a screen insert $(0.23 \times 0.25 \mathrm{~m})$. Generally snakes did not react to this handling and remained in a coiled position. Snakes that became active as a result of the handling were not used in the assay. After a 15-min interval during which the snake remained in a coiled position, water aerosol was sprayed directly onto the snake's head for $2 \mathrm{~s}$ at a distance of $0.30 \mathrm{~m}$ as a further control for delivery effects. Immediately after water aerosol application, the observer moved to a distance of $3 \mathrm{~m}$ and observed the snake for $5 \mathrm{~min}$. We reasoned that if the spray did not elicit a response within this period, it would be unlikely to do so even if longer periods were used. As a criterion for further testing, only non-responding snakes were used for further testing. Thus, if the snake was still in the coiled position at the end of the observation period it was then sprayed with a test stimulus for $2 \mathrm{~s}$ and observed for an additional $5 \mathrm{~min}$. After the observation period the snake was checked for alertness, ie the ability to right itself and strike at the observer. In general snakes were tested only once. However, some snakes were tested more than once ( 20 out of 367 trials) and only after a latency of at least 5 days when it had been determined that the snake expressed normal behavior and neurological reactions, ie the snake did not show any signs of morbidity, its pupils constricted when light was shined into them, the snake was aggressive and readily struck at the observer when approached, and it could right itself when turned upside down. Because the snakes were randomly reassigned for testing, any potential biases were assumed to be absorbed into experimental error.

Table 1. Summary of reactions by brown tree snakes to application of aerosols containing complex chemical mixtures derived from natural products

\begin{tabular}{|c|c|c|c|c|c|c|c|c|c|}
\hline \multirow[b]{2}{*}{ Extract } & \multirow[b]{2}{*}{$\mathrm{n}$} & \multirow[b]{2}{*}{ Code } & \multirow[b]{2}{*}{ Initial behavior ${ }^{a}$} & \multicolumn{2}{|c|}{ Initial latency (s) } & \multicolumn{2}{|c|}{$\begin{array}{c}\text { Duration (s) of vigorous } \\
\text { movement }\end{array}$} & \multicolumn{2}{|c|}{$\begin{array}{l}\text { Duration (s) of } \\
\text { slow movement }\end{array}$} \\
\hline & & & & $x$ & SEM & $x$ & SEM & $x$ & SEM \\
\hline Anise oil & 11 & ANS & VM & 13 & 19 & 122 & 62 & 114 & 53 \\
\hline Cedarwood oil & 10 & CDW & VM & 81 & 91 & 207 & 89 & 5 & 15 \\
\hline Cinnamon oil & 15 & CIN & VM & 4 & 1 & 150 & 38 & 94 & 26 \\
\hline Citronella oil & 5 & CIT & VM & 73 & 57 & 82 & 22 & 181 & 26 \\
\hline Clary sage oil & 10 & SAG & VM & 23 & 25 & 124 & 74 & 112 & 59 \\
\hline Ginger oil & 10 & GIN & SM & 83 & 83 & 4 & 10 & 195 & 100 \\
\hline Grapefruit oil & 10 & GRP & VM & 105 & 137 & 84 & 70 & 125 & 80 \\
\hline Juniper berry oil & 10 & JUN & VM & 87 & 117 & 133 & 109 & 110 & 113 \\
\hline Lavender oil & 10 & LVN & VM & 76 & 38 & 120 & 87 & 124 & 105 \\
\hline Oleo resin of Capsicum & 9 & CAP & SM & 296 & 5 & 0 & 0 & 4 & 11 \\
\hline Pennyroyal oil & 8 & PEN & VM & 13 & 2 & 37 & 28 & 73 & 38 \\
\hline Rosemary oil & 10 & RSM & VM & 65 & 39 & 172 & 126 & 74 & 89 \\
\hline Water & 10 & WAT & None & - & - & 0 & 0 & 0 & 0 \\
\hline Wintergreen oil & 10 & WNT & SM & 48 & 8 & 36 & 10 & 131 & 22 \\
\hline Yucca & 10 & YUC & None & - & - & 0 & 0 & 0 & 0 \\
\hline
\end{tabular}

a Initial behaviors are defined as: (VM) vigorous undirected violent movement characterized by the snake flailing its body and head against the walls of the container; (SM) slow directed movement characterized by the snake probing the corners of the container similar to naturally occurring investigatory behavior; (None) no gross motor action by the snake, with the snake remaining in its coiled position. 
Table 2. Summary of responses of brown treesnake to various natural products

\begin{tabular}{|c|c|c|c|c|c|c|c|c|c|}
\hline Chemical & Code & $\begin{array}{c}\text { CAS } \\
\text { number }\end{array}$ & $\mathrm{N}$ & $\begin{array}{l}\text { Reacting }^{\mathrm{a}, \mathrm{b}} \\
(\%)\end{array}$ & $\begin{array}{c}\text { Initial } \\
\text { movement }\end{array}$ & $\begin{array}{c}\text { Initial } \\
\text { latency } \\
\text { (s) ( }( \pm S E M)\end{array}$ & $\begin{array}{c}\text { Duration VM } \\
\text { (s) }( \pm S E M)\end{array}$ & $\begin{array}{c}\text { Duration SM } \\
\text { (s) ( } \pm \text { SEM) }\end{array}$ & $\begin{array}{c}\text { Total } \\
\text { movement } \\
\text { (s) }\end{array}$ \\
\hline Amyl acetate & AMAC & $628-63-7$ & 14 & $100.0 *$ & VM & $3( \pm 0)$ & $25( \pm 3)$ & $42( \pm 5)$ & $69( \pm 39)$ \\
\hline m-Anisaldehyde & AALD & 591-31-1 & 10 & $100.0 *$ & VM & $10( \pm 5)$ & $44( \pm 11)$ & $179( \pm 11)$ & $223( \pm 70)$ \\
\hline trans-Anethole & ANTH & $4180-23-8$ & 8 & $87.5 *$ & VM & $16( \pm 5)$ & $84( \pm 29)$ & $145( \pm 20)$ & $229( \pm 58)$ \\
\hline Camphor & CAM & 76-22-2 & 8 & 0.0 & VM & - & - & $0( \pm 0)$ & $0( \pm 0)$ \\
\hline Cineole & CINE & $470-82-6$ & 15 & $100.0 *$ & VM & $30( \pm 19)$ & $45( \pm 8)$ & $90( \pm 6)$ & $135( \pm 25)$ \\
\hline Cinnamaldehyde & CALD & $14371-10-9$ & 10 & $100.0 *$ & VM & $7( \pm 1)$ & $135( \pm 6)$ & $145( \pm 7)$ & $280( \pm 104)$ \\
\hline Cinnamic acid & CACD & 621-82-9 & 5 & 0.0 & NONE & - & - & $0( \pm 0)$ & $0( \pm 0)$ \\
\hline Citral & CITR & $5392-40-5$ & 9 & $100.0 *$ & VM & $9( \pm 2)$ & $112( \pm 22)$ & $133( \pm 22)$ & $244( \pm 82)$ \\
\hline Ethyl butyrate & EB & $105-54-4$ & 10 & 10.0 & SM & $134( \pm 46)$ & $9( \pm 1)$ & $42( \pm 1)$ & $52( \pm 4)$ \\
\hline Ethyl phenylacetate & EPAC & $101-97-3$ & 15 & $75.3^{*}$ & VM & $49( \pm 26)$ & $55( \pm 11)$ & $111( \pm 6)$ & $167( \pm 24)$ \\
\hline Eugenol & EUG & $97-53-0$ & 10 & $70.0 *$ & VM & $24( \pm 5)$ & $133( \pm 23)$ & $42( \pm 13)$ & $175( \pm 36)$ \\
\hline Geraniol & GERL & $106-24-1$ & 10 & 0.0 & NONE & - & - & $104( \pm 0)$ & $105( \pm 9)$ \\
\hline Geranyl acetate & GAC & $105-87-3$ & 10 & $100.0 *$ & VM & $15( \pm 3)$ & $103( \pm 29)$ & $120( \pm 27)$ & $223( \pm 59)$ \\
\hline$d$-Limonene & LIM & $5989-27-5$ & 10 & 27.7 & SM & $216( \pm 44)$ & - & $36( \pm 0)$ & $36( \pm 2)$ \\
\hline Linalool & LIN & 78-70-6 & 10 & 9.1 & SM & $106( \pm 42)$ & - & $105( \pm 0)$ & $105( \pm 10)$ \\
\hline Methone & MEN & $10458-14-7$ & 10 & $100.0 *$ & VM & $10( \pm 2)$ & $50( \pm 6)$ & $59( \pm 6)$ & $109( \pm 35)$ \\
\hline Methyl anthranilate & $\mathrm{MA}$ & $134-20-3$ & 15 & $86.9 *$ & VM & $109( \pm 36)$ & $35( \pm 14)$ & $45( \pm 4)$ & $80( \pm 8)$ \\
\hline Methyl salicylate & MS & $119-36-8$ & 10 & $100.0 *$ & VM & $10( \pm 1)$ & $39( \pm 8)$ & $150( \pm 7)$ & $189( \pm 60)$ \\
\hline Nerol & NER & $106-25-2$ & 10 & 10.0 & SM & $56( \pm 27)$ & - & $149( \pm 0)$ & $149( \pm 20)$ \\
\hline a-Pinene & PIN & $7785-26-4$ & 10 & $77.8 *$ & VM & $89( \pm 37)$ & $73( \pm 16)$ & $87( \pm 5)$ & $161( \pm 17)$ \\
\hline a-Terpinene & TER & 99-86-5 & 10 & 10.0 & VM & $194( \pm 44)$ & $11( \pm 11)$ & $55( \pm 1)$ & $59( \pm 4)$ \\
\hline
\end{tabular}

a The percentage of snakes reacting to application of the aerosol.

$b * P<0.05$ in binomial test where the percentage indicated is different from zero.

Behaviors were categorized by a trained observer as follows: VM was a violent, vigorous movement by snakes exposed to the aerosol. This movement was characterized by undirected flailing and vigorous probing of the creases of the test chamber. SM was characterized as a directed, slow search behavior, often accompanied by tongue flicks. This behavior could also be classified as investigatory behavior. In both cases the duration(s) of these behaviors was noted. The time from the application of the stimulus to the onset of either VM or SM was defined as the latency, LAT-VM and LAT-SM, respectively. For the purposes of analysis we used the latency to the first locomotory behavior, LAT, as the quantifiable metric. TOT was defined as the total amount of time (s) that a snake was engaged in locomotory behavior. The time spent in each locomotory behavior relative to the total active time was defined as \% VM and \%SM, respectively.

\subsection{Analyses}

We used a fixed effects analysis of variance for comparison across chemicals for each of the behavioral categories. In the first set of analyses, aerosol stimulus (ie essential oil) was the between measures effect, while each of the behavioral measures were dependent variables. We used a post hoc Tukey's Honest Significance Difference test to isolate differences among test stimuli for each of the behavioral measures. Similar analyses were performed for the single reagents. We also categorized reagents into groups that yielded similar combinations of behaviors using cluster analy- sis. ${ }^{46}$ Amalgamation of clusters was achieved using Ward's method. ${ }^{47}$ This approach is distinct from most clustering algorithms in that it uses an analysis of variance approach to evaluate the distances between clusters. The distance measure used was a Chebychev distance. This approach tends to maximize the number of clusters because it is sensitive to differences among objects along single dimensions. The behavioral dimensions considered were: VM, SM, LAT, TOT, $\% \mathrm{VM}$, and \%SM. All tests (reagent or essential oil) were run during the same time periods. Thus, only one set of negative controls, water and yucca, were conducted. Results from these assays were used in the essential oil analysis. No negative control data were included in the reagent analysis. However, we remind the reader that all snakes were required to meet a noresponse criterion to a water aerosol spray during the pre-treatment test (above).

\section{RESULTS}

\subsection{Aerosol tests for chemically complex natural extracts}

None of the snakes responded to being sprayed with water. Snakes did not show signs of a behavioral response when they were sprayed with a $10 \mathrm{~g} \mathrm{liter}^{-1}$ yucca solution, the emulsifier used in all tests. Thus, the pre-condition for the tests was met. Snakes responded differently to the various aerosol types for the following behaviors: VM $(F=10.825)$, SM $(F=$ 8.314), TOT $(F=18.127)$, and $\operatorname{LAT}(F=28.577)$, each with $d f=14,133, P<0.001$. 

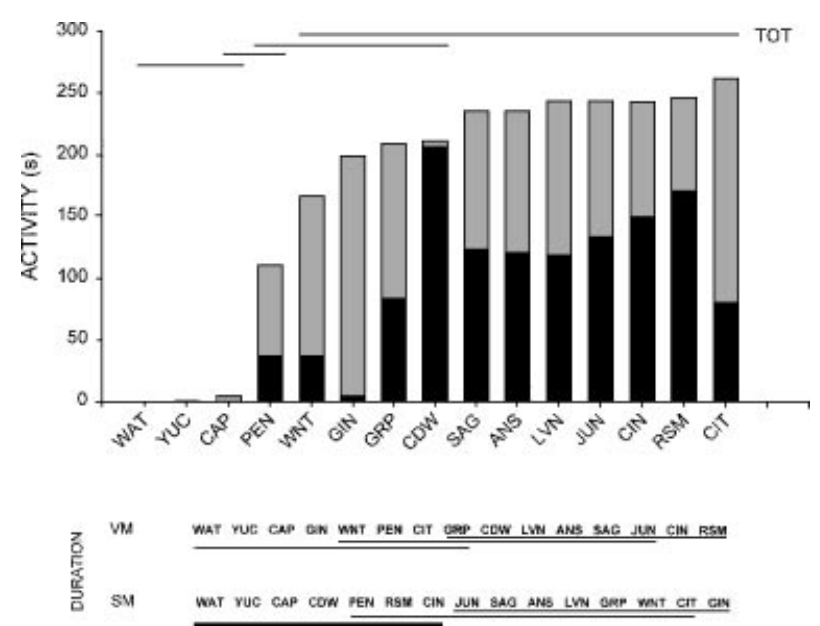

Figure 1. Comparison of mean behavioral responses by brown treesnakes as a function of essential oil aerosol. The time a snake was observed to be engaged in either slow, directed movement (SM) is depicted in grey, while the time spent in undirected, vigorous movement (VM) is depicted in black. Lines (inset) join statistically similar mean values for the total duration of movement (TOT, $P>0.05$ ) as determined by the Tukey's Honestly Significant Difference test with Spjotovoli-Stoline correction for unequal sample sizes. ${ }^{41}$ Other post hoc comparisons are made for duration of ranked activity for VM and SM behaviors (bottom insets). Codes for the essential oils are given in Table 1.

Snakes were not aroused when sprayed with a potent mammalian irritant, oleo resin of Capsicum. Snakes were only weakly aroused when sprayed with the bird and mammalian irritant pennyroyal oil (Table 1, Fig 1).

The remaining essential oils induced arousal and movement (TOT) in snakes for about the same proportion of the observation period, 56-87\%. However, the type of reaction and time observed for each reaction varied as a function of essential oil (Fig 1). At the extremes, the principal response for brown treesnakes sprayed with oil of cedarwood was a prolonged violent, undirected, vigorous movement. In contrast, the principal response by snakes sprayed with oil of ginger was a slow directed investigatory movement. Though reduced in duration, snakes sprayed with pennyroyal or wintergreen oil also responded largely with slower investigatory movements. The remainder of the solutions yielded a balanced mixture of movement types, ie VM and SM, with snakes initially exhibiting a high degree of hyperactivity that subsided into slower movement.

Generally snakes grew quiescent before the end of the observation period. However, there was no evidence of chemically induced immobilization as it might affect the snakes' defensive behavior. Snakes either coiled in response to being prodded or they struck at the observer. Two snakes sprayed with cinnamon oil died within $25 \mathrm{~h}$ of exposure, showing signs of respiratory hemorrhage. All the remaining snakes survived for at least 5 days post-treatment with no gross signs of illness or morbidity, after which time we stopped monitoring the snakes.

\subsection{Aerosol tests for single chemicals frequently found in natural extracts}

Responsiveness to the various reagent-based aerosol solutions varied widely (Table 2 , Fig 2 ). Overall, the response latencies of the snakes varied considerably across chemicals: latency to initial vigorous movement, $F=27.48, d f=20,198, P<0.001$; latency to initial slow movement, $F=9.68, d f=20,198, P<$ 0.001 . Amyl acetate was characterized by having the shortest latency to response. In post hoc tests, the compounds that produced movement latencies longer than amyl acetate $(P>0.05)$ were: ethyl butyrate,
Figure 2. Comparison of mean behavioral responses by brown treesnakes as a function of chemical aerosol. The time a snake was observed to be engaged in either slow, directed movement (SM) is depicted in grey, while the time spent in undirected, vigorous movement (VM) is depicted in black. Lines (inset) join statistically similar mean values for the total duration of movement (TOT, $P>0.05$ ) as determined by the Tukey's Honestly Significant Difference test with Spjotovoli-Stoline correction for unequal sample sizes. ${ }^{46}$ Other post hoc comparisons are made for duration of ranked activity for VM and SM behaviors (bottom insets). Codes for the chemicals are given in Table 2 .

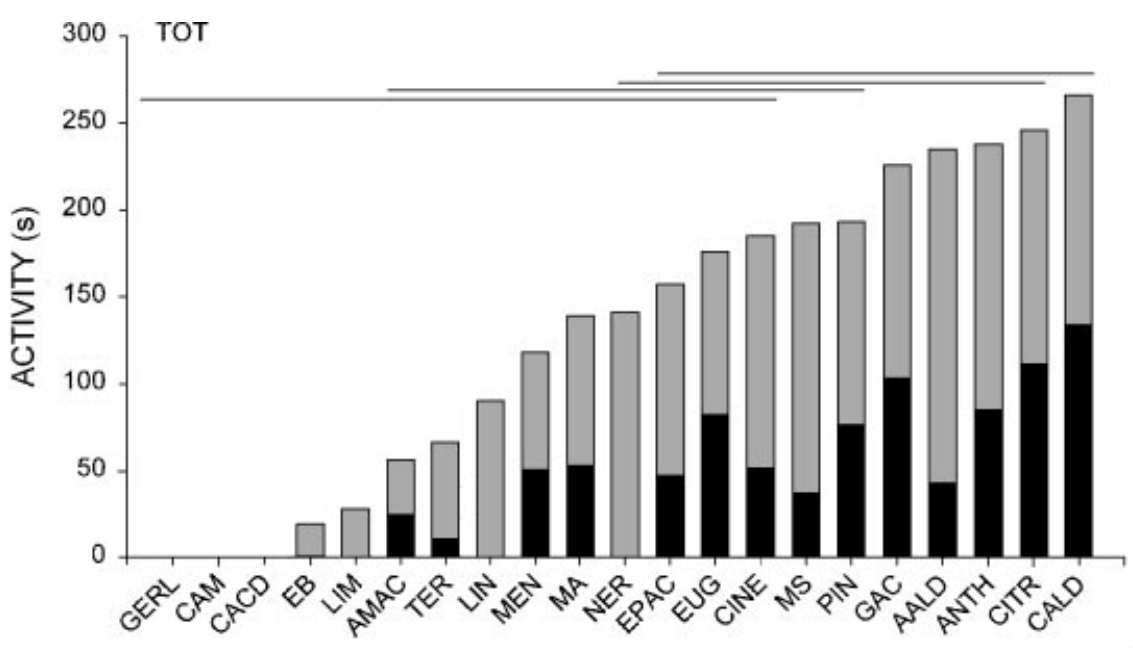

VM

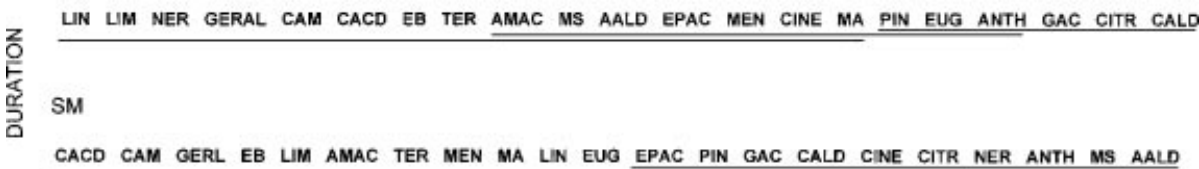


Table 3. Summary of behavior of brown treesnakes as a function of chemical clusters

\begin{tabular}{|c|c|c|c|c|c|}
\hline \multirow[b]{2}{*}{ Behavior $^{\mathrm{b}}$} & \multicolumn{5}{|c|}{ Cluster $^{\mathrm{a}}$} \\
\hline & $\begin{array}{c}l \\
n=3\end{array}$ & $\begin{array}{c}l l \\
n=4\end{array}$ & $\begin{array}{c}I I I \\
n=4\end{array}$ & $\begin{array}{c}I V \\
n=7\end{array}$ & $\begin{array}{c}V \\
n=3\end{array}$ \\
\hline VM & $43( \pm 9)$ & $52( \pm 19)$ & $3( \pm 3)$ & $82( \pm 14)$ & $0( \pm 0)$ \\
\hline SM & $61( \pm 16)$ & $115( \pm 10)$ & $48( \pm 16)$ & $145( \pm 9)$ & $0( \pm 0)$ \\
\hline LAT & $18( \pm 12)$ & $99( \pm 11)$ & $114( \pm 13)$ & $31( \pm 14)$ & $300( \pm 0)$ \\
\hline TOT & $104( \pm 26)$ & $167( \pm 12)$ & $51( \pm 17)$ & $227( \pm 11)$ & $0( \pm 0)$ \\
\hline$\%$ VM & $42( \pm 2)$ & $29( \pm 11)$ & $5( \pm 4)$ & $35( \pm 5)$ & $0( \pm 0)$ \\
\hline$\%$ SM & $58( \pm 2)$ & $71( \pm 11)$ & $95( \pm 4)$ & $65( \pm 5)$ & $0( \pm 0)$ \\
\hline
\end{tabular}

${ }^{a}$ Cluster values are the mean ( \pm SEM) behavioral response, i.e., time spent in activity (s) by brown treesnakes. $n$ is the number of compounds within each cluster.

${ }^{\mathrm{b}}$ Behaviors used in the cluster analysis were: VM, duration (s) of violent movement; SM, duration (s) of slow, methodical movement; LAT, latency (s) to first movement; TOT, duration (s) of all locomotory behavior; \% VM, time spent in violent movement relative to the total movement time; \% SM, time spent in slow movement relative to the total movement time. $d$-limonene, $a$-terpinene, linalool, nerol, geraniol, cinnamic acid and camphor. Snakes exposed to the latter three compounds did not move at all when sprayed. The length of time snakes expressed vigorous, undirected movement after exposure to aerosol also differed across chemicals $(F=9.91, d f=20,198, P<$ $0.001)$. Similarly, the length of time snakes expressed slow, directed movement after exposure to aerosols differed across chemicals $(F=5.93, d f=20,198, P<$ 0.001 ).

To make better sense of the diversity of response values shown in Table 2 , and to determine whether an underlying pattern of responses to reagents existed we performed a cluster analysis. Five categories of repellents were identified (Table 3, Fig 3). Brown treesnakes did not react to chemicals in cluster V: geraniol, camphor, and cinnamic acid, as indicated by a latency that equaled the total observation period. Cluster IV contains the most active chemicals, consisting of: trans-anethole, $m$-anisaldehyde, 1,4-cineole, cinnamaldehyde, citral, geranyl acetate and methyl salicylate. The snakes' reaction to cluster IV compounds was quick, characterized by a relatively long initial period of violent movement that then gave rise to an extended period of slow investigatory behavior.
Cluster II chemicals are moderately active and consist of: $\alpha$-pinene, ethyl phenylacetate, eugenol and nerol. These compounds produced long periods of slow movement. Snakes showed a slight delay in their reaction to being sprayed with Cluster II compounds and they were only active for about half of the observation period. As with Cluster IV compounds, the movement for Cluster II compounds was slow and methodical. Cluster III compounds are only weakly active, and consist of ethyl butyrate, limonene, linalool and $\alpha$-terpinene. While the initial reaction to cluster III compounds was quick, there was no apparent violent irritation response, and only a short-lived slow investigatory response by snakes. Chemicals in cluster I can also be considered highly irritating, but poor at promoting long-term locomotory behavior. Chemicals in cluster I consisted of amyl acetate, menthone and methyl anthranilate.

\section{DISCUSSION}

Although the flavor and aroma extracts used in this study contain hundreds of compounds, they are often characterized by one or two predominant chemicals that convey to human observers the general quality of
Figure 3. Groupings (I-V) of chemicals based on brown treesnake behavioral response profiles after a 2-s exposure to aerosols. Groups were calculated using Ward's method and a Chebychev distance matrix. Profiles of the means for the response variables for each group are indicated on the left. Codes for chemicals and response variables are given in Table 2 .
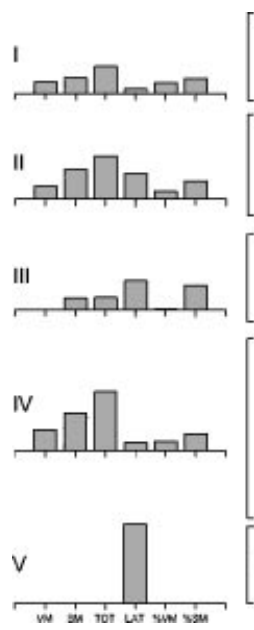

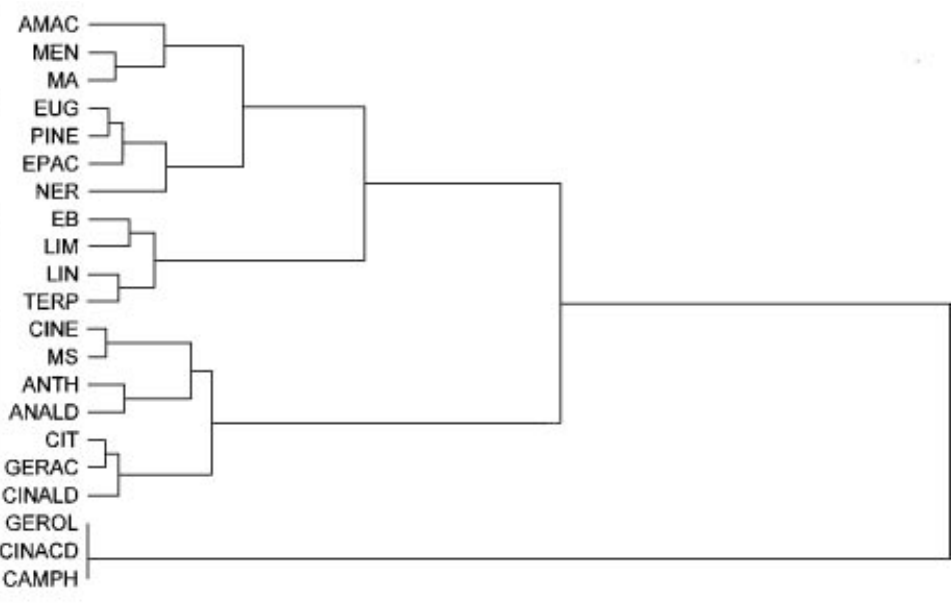


the extract. Thus, eugenol was assumed to be an adequate descriptor for clove oil, because it can make up to $90 \%$ of the essential oil. Pennyroyal oil is principally composed of $d$-pulegone (98\%). Eucalyptus oil is principally composed of 1,8-cineole (54-90\%). Cinnamaldehyde is an important component of cinnamon oil. Similarly, limonene can be generally considered an adequate model for the irritant potential of mandarin, tangerine, orange or grapefruit oils where the limonene content is around 72, 90, 96 and 95\%, respectively. It is arguable that by comparing Tables 1 and 2, while referencing various flavor and food codices, ${ }^{44}$ one could identify other essential oils or specific compounds that would be useful as snake irritants. For example, the behavioral responses to application of anise oil (licorice flavoring), transanethole and $m$-anisaldehyde (the principal sensory compounds of this oil conveying the 'sense' of licorice) all promoted similar behavioral responses by the snakes. Similarly, the activity induced by cinnamaldehyde (the principal aromatic in cinnamon oil) and cinnamon oil were concordant.

Identification of snake repellents from food and flavor ingredient sources has several advantages over those identified from other sources, eg petroleum distillates, fungicides, insecticides. First, the regulatory restrictions on the use of flavor ingredients as repellents may be lower or waived altogether under US environmental regulatory statutes. ${ }^{41}$ Second, food and flavor compounds are less likely to be harmful to human applicators at the concentrations needed to promote the desired response in snakes relative to compounds from other sources, ie synthetic pesticides or petroleum distillates. However, while the flavor ingredients may be less acutely toxic to human applicators, that does not necessarily imply that they are benign. Applicators should always exercise caution. Nonetheless, careful selection of a snake repellent from the list of essential oils and reagents considered here might yield active agents to which humans are less sensitive, thus making them appealing pest-management tools. For example, several of the reagents identified in this study as having snake-repellent properties are used as odorants in commercially available air fresheners. The concentrations of those odorants in those products is sufficient in many cases to produce the same behavioral patterns in snakes as detailed in this study.

Whether a compound is irritating to snakes or any other taxa will depend upon intrinsic biological factors, ie similarity of chemical structures, ${ }^{48,49}$ receptor specificity, ${ }^{50}$ concentration $^{51}$ and integration of neural input to form the perception of irritancy. ${ }^{52}$ Thus, there may be some compounds that are perceived as irritating for birds, mammals and reptiles, eg cinnamaldehyde. ${ }^{2,53}$ Alternatively, there are compounds that are irritating to only one taxon, or are mutually irritating to two taxonomic classes, but not to a third. For example, cinnamic acid and capsaicin are potent mammalian irritants, but they do not have such an effect for the brown treesnake or birds. ${ }^{2}$ Pulegone is a potent mammalian and bird irritant but is ineffective against the brown treesnake. ${ }^{54}$ Methyl anthranilate is a potent bird irritant but is relatively innocuous to mammals and the brown treesnake. ${ }^{55}$

Mason et $a l^{55}$ illustrated significant differences between the irritating properties of a variety of compounds for mammals and birds. Clark and Shah speculated on the receptor mechanism for such classlevel taxonomic differences, ${ }^{56}$ and have attempted to use molecular modeling techniques to characterize avian specific structure-activity relationships similar to those employed for mammalian irritants. ${ }^{49,50,57}$ However, in the absence of systematic data on irritancy and repellency attributes of chemicals for snakes, initial characterizations of snake repellents are largely left to empirical descriptions. This study adds to our empirical understanding of how reptiles might fit into a broader understanding of taxonomic differences and similarities for the perception of chemical irritants in snakes. All of these factors are important in developing pest-management tools that maximize target-specific efficacy, minimize environmental impact and reduce human health risks.

\subsection{Management implications}

There are many situations where snakes have been identified as being in crawl spaces, crevices, or in cargo. Often it is not practical to physically extract the snake. Similarly it is frequently not desirable to use a lethal fumigant. In those circumstances there is a need to fumigate the target space with a compound that will have low impact to the structure and humans yet be effective at driving the snake out of its refugium. The essential oils and reagents identified in this study may fulfill those needs. Aerosols or fumigants containing the identified ingredients would be useful as a tool in nuisance pest management as well as a tool for inspection and quarantine operations such as might occur cargo ports.

\section{ACKNOWLEDGEMENTS}

We appreciate the continued efforts and help from $\mathrm{H}$ Hirsh and others at Andersen Air Force Base, Guam. This research was conducted with funds provided to the National Wildlife Research Center by the US Department of Defense under Legacy Project Number 18, 'Field Evaluation of Chemical Methods for Brown Tree Snake Management' and the sustained support of the Legacy Program is greatly appreciated. All experiments were performed in compliance with Institutional Animal Care and Use guidelines. Identification and use of compounds and ingredients as snake repellents described in this study are US Patent Pending.

\section{REFERENCES}

1 FIFRA 40 Code of Federal Regulations 160 (1998). 
2 Clark L, Review of bird repellents. Proc Vertbr Pest Conf 18:330 337 (1998).

3 Savarie PJ and Bruggers RL, Candidate repellents, oral and dermal toxicants, and fumigants for brown treesnake control, in Problem snake management: the Habu and the brown treesnake, ed by Rodda GH, Sawai Y, Chiszar D and Tanaka H, Cornell University Press, Ithaca, NY, pp 417-422 (1999).

4 Tennyson JB, Napthalene based snake repellant, US Patent 5104900 (1992).

5 Savidge JA, Extinction of an island forest avifauna by an introduced snake. Ecology 68:660-668 (1987).

6 Rodda GH, Fritts TH and Conry PJ, Origin and population growth of the Brown Tree Snake, Boiga irregularis, on Guam. Pac Sci 46:46-57 (1992).

7 Fritts TH and Chizar D, Snakes on electrical transmission lines: patterns, causes, and strategies for reducing electrical outages due to snakes, in Problem snake management: the Habu and the brown treesnake, ed by Rodda GH, Sawai Y, Chiszar D and Tanaka H, Cornell University Press, Ithaca, NY, pp 89-104 (1999).

8 US Department of Agriculture, Brown treesnake control activities on Guam, Environmental Assessment, US Department of Agriculture, Washington, DC, USA (1996).

9 Savarie PJ, Shivik JA, White GA, Hurley JC and Clark L, Use of acetaminophen for large-scale control of brown treesnakes. $\mathcal{F}$ Wildl Manage 65:356-365 (2001).

10 Shiroma H, Experiment to determine the effective height of a wooden fence to prevent Habu (Trimeresurus flavoviridis) dispersal, in Reports of ecological researches to diminish bite of Habu (Trimeresurus flavoviridis) in Okinawa Prefecture, ed by Iha S, Vol 4, Department of Habu, Okinawa Prefectural Institute of Public Health, Ozato, Okinawa, Japan, pp 99-108 (1981).

11 Nishimura M, Improvements of 'Habu (Trimeresurus flavoviridis) fence', structure and height of net fence, in Reports of ecological researchers to diminish bite of Habu (Trimeresurus flavoviridis) in Okinawa Prefecture, ed by Iha S, Vol 6, Department of Habu, Okinawa Prefectural Institute of Public Health, Ozato, Okinawa, Japan, pp 71-83 (1983).

12 Nishimura $M$, Heights of building block and metal net fences to prevent invasion of Habu, Trimeresurus flavoviridis, in Reports of ecological researches to diminish bite of Habu (Trimeresurus flavoviridis) in Okinawa Prefecture, ed by Iha S, Vol 7, Department of Habu, Okinawa Prefectural Institute of Public Health, Ozato, Okinawa, Japan, pp 7-11 (1984).

13 Perry G, Campbell EW III, Rodda GH and Fritts TH, Managing island biotas: brown treesnake control using barrier technology. Proc Vertbr Pest Conf 18:138-143 (1998).

14 Nishimura $M$, Repellents and use of prey items for delivering toxicants for control of habu (Trimeresurus flavoviridis), in Problem snake management: The Habu and the brown treesnake, ed by Rodda GH, Sawai Y, Chiszar D and Tanaka H, Cornell University Press, Ithaca, NY, pp 158-167 (1999).

15 Hayashi Y, Hattori S and Tanaka H, The electric net trap for venomous snake, Habu, Trimeresurus flavoviridis. Fap $\mathcal{f}$ Exp Med 54:207-210 (1984).

16 Tanaka H, Hayashi Y, Kihara H, Hattori S, Mishima S, Wada Y, Kurosawa $\mathrm{M}$ and Sawai Y, Population control of Habu, Trimeresurus flavoviridis, the venomous snake, studied on Tokunoshima Island by a research group FY 1980 to 1983. Snake 19:26-40 (1987).

17 Aguon CF, Beck RE Jr and Ritter MW, A method for protecting nests of the Mariana crow from brown treesnake predation, in Problem snake management: The Habu and the brown treesnake, ed by Rodda GH, Sawai Y, Chiszar D and Tanaka H, Cornell University Press, Ithaca, NY, pp 460-467 (1999).

18 Campbell EW III, Barriers to movements of brown treesnake, in Problem snake management: the Habu and the brown treesnake, ed by Rodda GH, Sawai Y, Chiszar D and Tanaka H, Cornell University Press, Ithaca, NY, pp 306-312 (1999).

19 Johnson TW, Repelling rat snakes from wood duck boxes with chemical barriers. Ann Conf SE Assoc Fish Wildl Agencies: 37:49-55 (1983).

20 Takashi C, Seiichi S and Tatsuhiro N, Animal repellent made of resin, Japanese Patent 04046107 A (1992).

21 Secoy DM, Investigatory behaviour of plains garter snakes, Thamnophis radix (Reptilia: Colubridae), in tests of repellent chemicals. Canad f Zool 57:691-693 (1979).

22 Mitsutoshi N, Animal attracting and repellent aerosol composition, Japanese Patent 57064601 A (1982).

23 Tokuo $S$ and Saburo T, Snake repellent composition for repelling noxious life of tree, Japanese Patent 60078903 A (1985).

24 San Julian GJ and Woodward DK, What you wanted to know about all you ever heard concerning snake repellents. Proc East Wildl Damage Control Conf 13:243-248 (1985).

25 Junichi E, Takakazu D and Yoshihito O, Animal repellent, Japanese Patent 63060907 A (1988).

26 Ferraro DM, The efficacy of naphthalene and sulfur repellents to cause avoidance behavior in the plains garter snake, in Twelfth Great Plains Wildlife Damage Control Workshop Proceedings, ed by Masters RE and Huggins JG, Noble Foundation, Ardmore, Oklahoma, pp 116-120 (1995).

27 McCoid MJ, Campbell EW III and Alokoa BC, Efficacy of a chemical repellent for the brown treesnake (Boiga irregularis). Snake 25:115-119 (1993).

28 Bogert CM, The problem of snake control. How to tell whether the snake at your doorstep is really one of the dangerous ones, and what you can do about it if it is. Nat Hist 57:185-188 (1948).

29 Flattery M, An effective way to control snakes. Pest Control 17:16-18 (1949).

30 Stickle WH, Control of Snakes, US Fish Wildl Serv, Wildl Leaf No 345 (1953).

31 Brock EM, Toxicological feeding trials to evaluate the hazard of secondary poisoning to gopher snakes, Pituophis catenifer. Copeia, pp 244-245 (1965)

32 Katsuren S, Kuwae N and Nakata K, Efficiency of $\mathrm{KCl}$ to kill $\mathrm{Habu}$, Trimeresurus flavoviridis, in Reports of ecological researches to diminish bite of Habu (Trimeresurus flavoviridis) in Okinawa Prefecture, ed by Iha S, Vol 2, Department of Habu, Okinawa Prefectural Institute of Public Health, Ozato, Okinawa, Japan, pp 164-167 (1979).

33 Lehmann HD, On the use of the insecticide bromophos for reptile maintenance. Salamandra 6:50-52 (1970).

34 Hayashi Y, Kihara $\mathrm{H}$ and Tanaka H, Development of directions for use of chlordane. Snake 10:56-59, 99 (1978).

35 Kihara $\mathrm{H}$ and Yamashita $\mathrm{H}$, The lethal effects of pesticides on reptiles. Snake 10:10-15, 93-94 (1978).

36 Toriba M, Senbo S and Kosuge Y, New dermal toxicants and methods of application for venomous snakes, in Problem snake management: the Habu and the brown treesnake, ed by Rodda GH, Sawai Y, Chiszar D and Tanaka H, Cornell University Press, Ithaca, NY, pp 411-416 (1999).

37 Uhler FM, Facts about snakes, US Fish Wildl Serv, Wildl Leaf No 257 (1951).

38 Brock EM and Howard WE, Control methods for snakes. Proc Vertbr Pest Conf 1:18-31 (1962).

39 Bond EJ, Manual of fumigation for insect control, FAO Plant Production and Protection Paper 54, Food and Agriculture Organization of the United Nations, Rome (1984).

40 Rodda GH, Fritts TH, Clark CS, Gotte SW and Chiszar D, A state-of-the-art trap for the brown treesnake, in Problem snake management: the Habu and the brown treesnake, ed by Rodda GH, Sawai Y, Chiszar D and Tanaka H, Cornell University Press, Ithaca, NY, pp 268-305 (1999).

41 FIFRA 40 Code of Federal Regulations 25(b) (2) (1994).

42 Mason JR and Clark L, Nonlethal repellents: the development of cost-effective, practical solutions to agricultural and industrial problems. Proc Vertbr Pest Conf 15:115-129 (1992).

43 Linnell MA, Engeman RM, Pitzler ME, Watton MO, Whitehead GF and Miller RC, An evaluation of two designs of 
stamped metal trap flaps for use in operational trapping of brown treesnakes (Boiga irregularis). Snake 28:14-18 (1998).

44 Bisset NG, Herbal drugs and phytopharmaceuticals, CRC Press, Boca Raton, Florida (1994).

45 Furia EE and Bellanca N, Fenaroli's Handbook of Flavor Ingredients, CRC Press, Cleavland, OH (1975).

46 Statistica, StatSoft, Tulsa, Oklahoma (1994).

$47 \mathrm{Ward} \mathrm{JH}$, Hierarchical grouping to optimize an objective function. F Amer Stat Assoc 58:236 (1963).

48 Mason JR, Bean NJ, Shah PS and Clark L, Taxon-specific differences in responsiveness to capsaicin and several analogs: correlates between chemical structure and behavioral aversiveness. F Chem Ecol 17:2539-2951 (1991).

49 Clark L, Physiological, ecological, and evolutionary bases for the avoidance of chemical irritants by birds. Curr Ornithol 14:1-37 (1998).

50 Clark L and Shah PS, Tests and refinements of a general structure-activity model for avian repellents. $\mathcal{F}$ Chem Ecol 20:321339 (1994).

51 Walker JC, Walker DB, Tambiah CR and Gilmore KS, Olfac- tory and nonolfactory odor detection in pigeons: elucidation by a cardiac acceleration paradigm. Physiol Behav 38:575-580 (1973).

52 Bryant BP, Savchenko A, Clark L and Mason JR, Potential for cell culture techniques as a wildlife management tool for screening primary repellents. Intnatl Biodeterior Biodegrad 45:175-181 (1999)

53 Windholz M, The Merck Index, Merck and Co Inc, Rahway, NJ (1983).

54 Mason JR, Evaluation of D-pulegone as an avian repellent. $\mathcal{F}$ Wildl Manage 54:130-135 (1990).

55 Mason JR, Adams MA and Clark L, Anthranilate repellency to starlings: chemical correlates and sensory perception. $\mathcal{f}$ Wildl Manage 53:55-64 (1989).

56 Clark L and Shah PS, Nonlethal bird repellents: in search of a general model relating repellency and chemical structure. $\mathcal{F}$ Wildl Manage 55:538-545 (1991).

57 Nielsen GD, Mechanisms of activation of the sensory irritant receptor by airborne chemicals. Toxicol 21:183-208 (1991). 